Running head: School support and teacher motivation

\title{
School support and teacher motivation to implement project-based learning
}

\author{
Shui-fong Lam ${ }^{\mathrm{a}, *}$, Rebecca Wing-yi Cheng ${ }^{\mathrm{b}}$, Harriet C. Choy ${ }^{\mathrm{a}}$ \\ ${ }^{a}$ Department of Psychology, the University of Hong Kong, Pokfulam Road, Hong Kong \\ ${ }^{b}$ Department of Educational Psychology, Counselling and Learning Needs, the Hong Kong \\ Institute of Education, 10 Lo Ping Road, Tai Po, New Territories, Hong Kong.
}

\begin{abstract}
The present study investigated how school support was related to teachers' motivation and willingness to persist in project-based learning. The participants were 182 Hong Kong teachers who completed a questionnaire about their school's support and their motivation to implement project-based learning. The results of structural equation modeling indicated that when teachers perceived their schools as being stronger in collegiality and more supportive of teacher competence and autonomy, they had higher motivation in project-based learning and stronger willingness to persist in this educational innovation. Perceived school support predicted teachers' attitude for future persistence both directly and indirectly through its influence on teacher motivation. The results suggest that social-contextual factors are important for teacher motivation in the implementation of educational innovations.
\end{abstract}

Key words: Project-based learning; School support; Teacher motivation; Self-determination theory; Education reform

* Corresponding author.

E-mail address: lamsf@hkusub.hku.hk (S.-f. Lam) 


\section{Introduction}

Project-based learning has been designated as a key educational innovation in the recent education reform in Hong Kong (Education Commission, 2000). Like the large-scale education reforms that have been launched since the 1990s in many western countries (Fullan, 2000; Kim, 2004), the recent Hong Kong education reform has been propelled by a strong demand from society that students should learn how to meet the challenges of a knowledge-based and fast-changing society. Schools are required to promote not only students' subject-matter knowledge but also general skills, such as critical thinking or collaborative skills. To equip students with skills in critical thinking, collaboration, communication, and problem solving, teachers are encouraged to use more student-centered teaching approaches. Project-based learning is one of the student-centered approaches which are highly recommended by the Hong Kong education reform. According to the Hong Kong curriculum reform proposal, project-based learning is described as a teaching strategy that would «enable students to connect knowledge, skills, values, and attitudes and to construct knowledge through a variety of learning experiences» (Curriculum Development Council, 2001, p. 87).

The aim of the present study was to investigate the factors that contribute to teacher motivation in the implementation of project-based learning. Previous research has suggested a number of factors that may influence the degree to which teachers will persist in an educational innovation. These factors can be classified into two broad categories: (a) teacher personal factors and (b) school contextual factors. Teacher personal factors include congruence between the innovation and the teacher's philosophy of education (Briscoe, 1991; Rich, 1990), teacher's self-efficacy (Ohlhausen, Meyerson, \& Sexton, 1992; Ross, 1994), and teacher's perceived value of the innovation and expectancy of success (Abrami, Poulsen, \& Chambers, 2004). School contextual factors include practical constraints, such as class size and time requirements (Sleeter, 1992), the management style of the principal (Zeichner, 1991), and the influence of school culture (Fullan \& Hargreaves, 1997). We investigated whether schools, which are perceived by teachers as collegial and supportive of teachers' competence and autonomy, tend to have teachers who are motivated in the implementation of project-based learning. We focused on school support because of the significant role of environment in influencing human behaviors (Lewin, 1936). We believe that school support, a contextual factor, is intricately related to teacher motivation, a personal factor.

\subsection{Project-based learning}

Project-based learning is part of the instructional approach originating from Dewey (1938), who stressed the importance of practical experience in learning. In project-based learning, students work in small groups on academic tasks. The task can be in the form of investigation or research on a particular topic. The topic being studied usually integrates concepts from a number of disciplines or fields of study. Students in the same small group collaborate with one another to reach a collective outcome over a period of time. They pursue solutions to a problem by asking and refining questions, debating ideas, making predictions, collecting and analyzing data, drawing conclusions, and communicating their findings to others. This approach is widely believed to be a powerful teaching strategy that would enhance student motivation and promote self-directed learning (Blumenfeld et al., 1991). 
Although project-based learning is regarded highly as an effective educational innovation in this time of education reform, it is not readily accepted by all teachers in Hong Kong. Watkins and Biggs (2001) have poignantly commented that many innovations imported from the West to Hong Kong are like organ transplants that are rejected. Project-based learning, as a new teaching approach from the West, is expected to encounter skepticism and even resistance from local teachers whose cultural background is different from that of their western counterparts. A recent study (Tse, Lam, Lam, \& Loh, 2005) has shown that, although student-centered approaches are officially recommended, most Hong Kong Chinese language teachers still employ teacher-led approaches in their teaching. Their reluctance is understandable. The new practices bear little resemblance to either their current practices or to the way they have learned and experienced teaching as students themselves. Indeed, the challenges of implementing project-based learning are not unique to Hong Kong but occur around the world where student-centered reform is advocated (Carrera, Tellez, \& D’Ottavio, 2003; Saye \& Brush, 2004).

\subsection{School support and teacher motivation}

While the benefits of project-based learning for students remain to be seen, few would argue that a key factor contributing to its successful implementation in the local setting hinges on teacher motivation. Project-based learning will have a better chance to bring about the desired benefits for students if teachers have a strong motivation to experiment with, and improve it in the classroom. Abrami et al. (2004) point out that an educational innovation often meets with a wide range of teacher receptivity. Some teachers may apply the innovation with great enthusiasm and persistence until it becomes fully integrated into their teaching. However, some may never try the new teaching strategy or may return to their old teaching practice after only a few initial attempts. It is important to find out why teachers vary in their motivation in implementing educational innovations. The knowledge in this respect is useful for the educators who are eager to improve instructional methods by educational innovations.

In the present study, we investigated three dimensions of school support: (a) competence support, (b) autonomy support, and (c) collegial support. We focused on these three dimensions on the basis of self-determination theory (Ryan \& Deci, 2000), an influential theory in the field of motivation. Ryan and Deci (2000), the leading proponents of self-determination theory, postulate that the needs for competence, autonomy, and relatedness are three fundamental and universal needs of people. According to Deci and Ryan (2000), the need for competence refers to the need to engage in optimal challenges and experience mastery in one's endeavors; the need for autonomy refers to the need to experience oneself as the initiator of action and to self-regulate one's own behaviors; and the need for relatedness refers to the need to seek attachments and experience feelings of security, belongingness, and intimacy with others. Deci and Ryan (2000) argue that satisfaction of these basic psychological needs provides the nutriments for motivation. Therefore, social environments can facilitate or forestall motivation by either supporting or thwarting people's needs for competence, autonomy, and relatedness.

The motivation that is facilitated or forestalled includes both extrinsic and intrinsic motivations. Extrinsic motivation refers to engaging in an activity as a means to an end that is outside the activity (e.g., getting praise or avoiding blame) whereas intrinsic motivation refers to performing an activity as an end in itself (i.e., for 
inherent pleasure). Despite the stark contrast between extrinsic and intrinsic motivations, Ryan and Deci (2000) do not conceptualize them as a dichotomy. Instead, they regard them as a continuum reflecting various degrees of self-determination. This continuum ranges from doing something out of heteronomy (i.e., external obligation) at one end to doing something out of autonomy (i.e., internal desires) at the other end. However, extrinsic motivation does not necessarily entail heteronomy. If people can internalize the external obligation, their extrinsically motivated behaviors can be autonomous. Self-determination theory postulates that people will experience more self-determination if their regulation involves a higher degree of internalization. External, introjected, and identified regulations are forms of extrinsic motivation but they vary in the degree of self-determination. External regulation involves the least internalization, with behaviors controlled by external forces. Introjected regulation involves a partial internalization, with behaviors performed to protect self-esteem or to avoid anxiety. Identified regulation involves a higher degree of self-determination because people tend to recognize and accept the value of a personally important behavior. However, identified regulation still has a lower degree of self-determination than intrinsic motivation which refers to having inherent enjoyment in performing the behaviors. According to self-determination theory, social environments that support people's innate needs for competence, autonomy, and relatedness will promote the development of intrinsic motivation as well as the internalization of extrinsic motivation (Ryan \& Deci, 2000).

\subsubsection{Need for competence in teachers}

Many early experiments showed that positive feedback enhanced intrinsic motivation (Boggiano \& Ruble, 1979; Deci, 1971) whereas negative feedback decreased it (Deci \& Cascio, 1972). Ryan and Deci (2000) explain these results with reference to the need for competence. They argue that social-contextual events, such as positive feedback, can induce feelings of competence during action, and thus can enhance intrinsic motivation for that action. They further argue that internalization of extrinsically motivated activities is also a function of perceived competence. People are more likely to engage in activities in which they feel efficacious. In the integrated model of teacher motivation (Jesus \& Lens, 2005), teachers were found to have high motivation in teaching or professional engagement if they had high expectancy of success or efficacy. Similarly, Malmberg (2008) also found that student teachers' control-expectancy beliefs (i.e., the belief that one is generally able to support children's learning) were related to increases in their mastery goal orientation. In the present study, teachers' competence support by their schools was conceptualized as perceptions of their schools having made proper arrangements to facilitate their success in the implementation of project-based learning (e.g., good coordination, reasonable workload, adequate staff development).

\subsubsection{Need for autonomy in teachers}

Previous research has also demonstrated the pivotal role of autonomy in teachers' intrinsic motivation. Pelletier, Séguin-Lévesque, and Legault (2002) found that the more teachers perceived pressure from above (i.e., they had to comply with a curriculum, with colleagues, and with performance standards) and pressure from below (i.e., they perceived their students to be unmotivated), the less their teaching was intrinsically motivated. In a similar vein, Malmberg (2008) found that the autonomy-enhancing aspects of teacher training promoted mastery goal orientation. He pointed out that the mastery goals of student teachers increased during the third 
year of their training when they could focus on self-selected areas of specialization and have more self-directed studies. In addition, Schaarschmidt (2005) also found that German teachers rated the motive to "act autonomously" as strongest in terms of personal significance among 22 work-related motives.

In view of the above findings, it is understandable why Evertson and Weinstein (2006) warn that teachers may lose the joy in their occupation if too much regimentation and external interference complicate their pedagogic objectives and self-determined professional goals. It is also understandable why Roth, Assor, Kanat-Maymon, and Kaplan (2007) urge educators to consider various educational and administrative processes that might affect teachers' sense of autonomy. On the basis of self-determination theory (Ryan \& Deci, 2000), autonomy is required for intrinsic motivation and can facilitate internalization of extrinsically motivated activities. In the present study, teachers' autonomy support by their school was conceptualized as teachers' perceptions of their schools being supportive of their autonomy during the implementation of project-based learning (e.g., allowed freedom in participation, involved them in decision making, acknowledged their opinions).

\subsubsection{Need for relatedness in teachers}

Among the three basic psychological needs, the need for relatedness is most relevant to the internalization of extrinsic motivation. Ryan and Deci (2000) postulate that, to many people, extrinsically motivated behaviors are uninteresting, and the primary reason for them to engage in such behaviors is probably because these behaviors are prompted, modeled, or valued by significant others to whom they feel attached or related. Previous research has shown that relatedness, the need to feel belongingness and connectedness with others, is an important catalyst for internalization. For example, Ryan, Stiller, and Lynch (1994) showed that children who felt securely attached to their parents and teachers tended to have higher internalization of the regulation process for positive school-related behaviors. Although the need for relatedness is most relevant to internalization of extrinsically motivated behaviors, it can also facilitate intrinsic motivation.

Ryan and Deci (2000) point out that intrinsic motivation tends to flourish in contexts characterized by a sense of security and relatedness. Therefore, intrinsic motivation is more likely to increase if a sense of security and relatedness is present in one's contexts. For example, Ishler, Johnson, and Johnson (1998) found that teachers' long-term implementation of cooperative learning was related to their involvement in collegial teaching teams and the support they received from colleagues and administrators. Lam and Lau (2008) also found that when teachers perceived higher collegiality in their schools, they were more willing to participate in peer coaching. In addition, Lam, Yim, and Lam (2002) also indicated that genuine collaboration among teachers in peer coaching could relieve teachers from psychological pressure because they had a sense of collective responsibility and shared ownership of the lesson. In the present study teachers' relatedness support by their school was conceptualized as teachers' perceptions of strong collegial support provided by their schools during the implementation of project-based learning. This may be particularly true for Hong Kong teachers who grew up in a collectivist culture that treasures interdependence (Markus \& Kitayama, 1991).

\subsection{The present study}

The present study was based on self-determination theory, a framework that 
postulates the cultural universality of psychological needs for competence, autonomy and relatedness (Ryan \& Deci, 2000). However, the cultural universality of these needs has been challenged in recent years. For example, Iyengar and Lepper (1999) have queried the significance of autonomy in collectivist culture. In a series of cross-cultural studies, they found that the lack of choice only diminished the motivation of Anglo-American children but not Asian-American children. Similarly, Bao and Lam (2008) also found that freedom of choice mattered less if Chinese children felt attached to the adults who made choices for them. As Asians are more likely to endorse interdependent self-construal (Markus \& Kitayama, 1991), they may have internalized the demands of the people to whom they feel attached, and thus they still feel autonomous even though they do not have choice.

The present study was conducted in Hong Kong, a Chinese society. Its non-Western cultural setting provides a valuable platform to test the claim of universality by the self-determination theory. It was examined whether competence, autonomy and relatedness would play an important role in teacher motivation and whether school that was strong in collegiality and supportive of teachers' competence and autonomy would tend to have teachers who were motivated in the implementation of project-based learning, an educational innovation. In short, it was investigated whether school support would be related to teachers' motivation in project-based learning and their attitude for future persistence.

\subsubsection{Hypotheses}

If the needs for competence, autonomy, and relatedness are universal, school support for these needs would predict teacher motivation, which in turn would predict teacher attitude for future persistence in project-based learning. The above expectation could be delineated by two hypotheses: (a) School support would have indirect effect on teacher attitude for future persistence through its influence on teacher motivation, i.e., teacher motivation would mediate the effect of school support on teacher attitude (Hypothesis 1); (b) School support would also have direct effect on teacher attitude despite the mediation effect of teacher motivation. This is so because school-related mechanisms probably account for the association between school support and teacher persistence (Hypothesis 2). This association might exist without involving teacher motivation. For example, school support is related to the actual infrastructure provided by the school like class size, workload allocation and financial resources, which might affect their persistence in the educational innovation.

The theoretical model depicting the above hypothesized effects is presented in Figure 1 (see Results section).

\section{Method}

\subsection{Context of the study}

The study took place in eight schools which varied in districts, socioeconomic backgrounds, and academic standards. In response to the curriculum reform in Hong Kong (Curriculum Development Council, 2001), these schools implemented project-based learning, a teaching strategy that was new to the teachers. To assess the effectiveness of this educational innovation, the administrators of these schools invited our research team at a local university to conduct an evaluation. The data reported in this paper are part of the data collected for this evaluation project. In these schools, five to six students were assigned to a small group that studied a topic of 
interest under the supervision of a teacher. The topics of the projects were diverse and multi-disciplinary in nature (e.g., air pollution in Hong Kong, teenager hip-hop culture, and the history of a local temple). These projects mostly lasted for two to three months. At the end of the project each group of students was required to submit a written report and to give an oral presentation on what they had learned about the topic.

Although the format of project-based learning was more or less the same across the eight schools, the way it was implemented could be different. First, teachers' participation in project-based learning was not entirely voluntary across the eight schools. In some schools, participation was solicited by middle management. We guessed that many teachers might not feel comfortable to decline such invitation although they could do so. Second, the training for teachers on project-based learning varied across schools. Some schools provided training to all teachers in a one-day or two-day workshop, some only sent the core members of the teaching team to attend seminars organized by education authorities, while others simply had informal sharing among teachers. Third, although all schools prepared some sorts of documents (e.g., general guidelines for supervision, student handbook, assessment criteria of students' performance) to support teachers in the implementation of project-based learning, the documents were more detailed in some schools while less detailed in the others. Fourth, the policy regarding the workload reduction of teachers was also varied across schools. It varied from cutting the after-school remedial class or canceling the school open day to no workload reduction. Some schools scheduled a time slot for project-based learning in their weekly time table but some schools did not do so. Last but not least, financial support also varied across the eight schools. For example, while most schools did not provide financial support directly to students, one school allocated HK\$100 to each group of students for the preparation.

\subsection{Participants}

The participants were 182 Chinese teachers (107 female and 75 male) from eight secondary schools in Hong Kong. To relieve the participants from the apprehension that their responses would be identified, the questionnaire was anonymous and no personal information about their age, experience, rank, and specialty was collected. However, based on school records, teachers' age ranged from 23 to 55 years and their specialties varied.

\subsection{Measures}

\subsubsection{Perceived school support}

An inventory was developed for the needs of the present study to measure teachers' perceptions of their school support (see Appendix A). The Perceived School Support inventory was composed of 15 items that were grouped into 3 subscales of five items each. Each subscale measured one aspect of school support, which has features that satisfy teachers' needs as identified in self-determination theory (Ryan \& Deci, 2000).

The Competence Support subscale measured the extent to which teachers perceived their schools as providing sound structure and making appropriate arrangements to facilitate their success in the project-based learning program; example item is "There was good coordination in my school so that I could complete my task smoothly”. The Autonomy Support subscale measured the extent to which 
teachers perceived their schools as supportive of their autonomy in implementing project-based learning; example item is "I felt that my opinions were respected in the process". Finally, the Collegial Support subscale measured teachers' perceptions of the level of collegial support they had received during the implementation; example item is "I got encouragement from my colleagues when I encountered difficulties in project-based learning”.

Teachers were asked to indicate their agreement to each statement on a 6-point Likert-type scale, ranging from 1 (strongly disagree) to 6 (strongly agree). The Cronbach's alphas of the Competence Support, Autonomy Support, and Collegial Support subscales were .88, .83, and .91, respectively. For the present study, the three subscale scores were used as three indices of school support. The Cronbach's alpha of the whole scale was .90 , indicating a high level of internal consistency.

Two confirmatory factor analyses were conducted on the 15 items with LISREL 8.8 (Jöreskog \& Sörbom, 2007). The first was a one-factor model with all the 15 items in one factor and the second was a three-factor model with five items in three corresponding factors. Results of the analyses favored the three-factor model, $\chi^{2}(87$, $\underline{\mathrm{N}}=182)=178.05, \underline{\mathrm{p}}<.001$, Comparative Fit Index $(\mathrm{CFI})=.98$, Standardized Root Mean Residual $($ SRMR) $=.043$, and Akaike's Information Criterion $($ AIC) $=244.05$, over the one-factor model, $\square \chi^{2}(90, \underline{N}=182)=435.04, \underline{p}<.001$, CFI $=.93$, SRMR $=.064$, and $\mathrm{AIC}=495.04$.

\subsubsection{Attitude for future persistence}

Two items measured the teachers' willingness to continue with project-based learning in their schools: (a) "Having considered the time I have spent and the stress I have experienced, I am still willing to support my school in implementing project-based learning" and (b) "Given freedom to choose, I shall not participate in similar activities.” These items were phrased in this format because we knew from some teachers in informal interview that their participation in the project-based learning was not entirely voluntary. Participation meant extra workload and might imply time pressure and stress for teachers. To measure teachers' attitude for further participation under these possible unfavorable conditions, they were asked to indicate their agreement to these two items on a 6-point Likert-type scale, ranging from 1 (strongly disagree) to 6 (strongly agree). The second item was reversed in coding for the measurement of this variable. The zero-order correlation between these two items was .72.

\subsubsection{Teacher motivation}

An inventory was developed for the needs of the present study to measure teachers' motivation in implementing the project-based learning activity. Teachers were asked to indicate the reasons for their participation. The Teacher Motivation inventory was modeled after the Self-Regulation Questionnaire (Ryan \& Connell, 1989) and had a focus on the teachers' experience of their participation in the project-based learning.

The inventory was composed of 20 items (see Appendix B) grouped in 4 subscales that measure the motivational constructs identified by Deci and Ryan (1985, 1991). These constructs can be placed on a continuum according to the extent they reveal self-determination. From the least self-determined to the most self-determined the subscales measure (a) extrinsic motivation by external regulation (e.g., "I participated because my supervisor would be upset if I didn't”), (b) extrinsic motivation by introjected regulation (e.g., "I participated because I don’t want others 
to think that I am incapable of doing it"), (c) extrinsic motivation by identified regulation (e.g., "I participated because it is helpful to my students"), and (d) intrinsic motivation (e.g., "I participated because learning new teaching approaches is enjoyable"). Integrated regulation was not included in the present study because it was difficult to distinguish between identified and integrated motivations using self-reports (Roth et al., 2007). Previous research on self-determination theory (Pelletier et al., 2002; Ryan \& Connell, 1989) did not include integrated regulation as well.

Teachers were asked to indicate their agreement to each item on a 6-point Likert-type scale, ranging from 1 (strongly disagree) to 6 (strongly agree). The Cronbach's alphas of the External Regulation, Introjected Regulation, Identified Regulation, and Intrinsic Motivation subscales were .79, .62, .91, and .88, respectively.

Results of confirmatory factor analysis on the 20 items marginally supported the four-factor structure, $\square \chi^{2}(164, \underline{\mathrm{N}}=182)=618.27, \mathrm{p}<.001$, CFI $=.92$, SRMR $=.17$, and AIC $=710.27$. The results were not satisfactory enough as SRMR was higher than .10. Yet, this four-factor structure was still adopted because CFI was high and it was derived from the self-determination theory. In addition, the simplex structure among these four subscales was acceptable.

To confirm the simplex structure among the four subscales (Guttman, 1954; Roth et al., 2007; Ryan \& Connell, 1989), the correlations between each type of teacher motivation and the two external criteria, namely the positive and negative attitudes for future persistence were examined. The former was indicated by the first item in teacher's attitude for future persistence whereas the latter was indicated by the second item. The positive attitude for future persistence was expected to correlate positively with high self-determined motivation while the negative attitude for future persistence was expected to relate positively with low self-determination. Thus, if the four types of teacher motivation really fell along a continuum that represented the different levels of self-determination, the correlations of the four subscales with positive attitude for future persistence should be positive with intrinsic motivation rather than with extrinsic. By contrast, the correlations with negative attitude for future persistence should be positive with extrinsic motivation rather than with intrinsic. In addition, the correlation coefficients with the adjacent types of motivation along the continuum should be significantly different. Results of the correlation analyses in Table 1 indicated the expected pattern of correlations.

To determine the significance of the difference between adjacent correlation coefficients along the continuum, we used the formula suggested by Cohen and Cohen (1983) to yield the t-statistic. Results indicated a significant difference between the correlations of negative attitude with external regulation and introjected regulation, $\underline{\mathrm{t}}=$ $4.74, \mathrm{p}<.01$, and also a significant difference between the correlations of negative attitude with introjected regulation and identified regulation, $\underline{\mathrm{t}}=11.73, \underline{\mathrm{p}}<.01$. In a similar vein, there was a significant difference between the correlations of positive attitude with external regulation and introjected regulation, $\underline{\mathrm{t}}=3.94, \mathrm{p}<.01$, and also a significant difference between the correlations of positive attitude with introjected regulation and identified regulation, $\underline{\mathrm{t}}=10.22, \mathrm{p}<.01$. However, the distinction between identified regulation and intrinsic motivation was not significant. At most, there was a marginally significant difference between the correlations of negative attitude with identified regulation and intrinsic motivation, $\underline{\mathrm{t}}=1.87, \mathrm{p}=.06$.

Insert Table 1 about here 
In the present study, five indices of teachers' level of self-determination toward the project-based learning program were computed according to the procedure recommended by Pelletier et al. (2002). We used the five indices instead of the original subscale scores because the former carried the same direction and weight whereas the latter did not. In fact, the external regulation and introjected regulation carried two different negative weights in the measurement of self-determination. According to Pelletier et al. (2002), each index was created by using an item from each subscale and by giving a weight to each item as a function of its degree of self-determination on the continuum. The first item from each subscale was used for index 1, the second for index 2, and so on. External and introjected regulations were assigned weights of -2 and -1 , respectively. In contrast, intrinsic motivation and identified regulation were assigned weights of 2 and 1 respectively. The maximum score of the index was 15 , that is, $(2 \times 6)+(1 \times 6)-(1 \times 1)-(2 \times 1)$; the minimum score was -15 , that is, $(2 \times 1)+(1 \times 1)-(1 \times 6)-(2 \times 6)$; the mean was 0 . As there were five items per subscale, we generated five indices of teachers' level of motivation towards the project-based learning program. High indices indicated high self-determination whereas low indices indicated low self-determination. The Cronbach's alpha of the variable Teacher Motivation based on these five indices was .91, indicating a high level of internal consistency. Results of confirmatory factor analysis supported that these five indices tap the same latent construct, $\chi^{2}(5, \underline{N}=182)$ $=8.32, \mathrm{p}>.05, \mathrm{CFI}=1.00, \mathrm{SRMR}=.018$, and $\mathrm{AIC}=28.32$. These indices indicated $\mathrm{a}$ very good fit of the model of five indices (Hu \& Bentler, 1999).

\subsection{Procedure}

All the teachers $(\underline{\mathrm{N}}=212)$ who had participated in the project-based learning program were invited to complete a questionnaire one or two weeks after their students had completed the projects. They completed the questionnaire either at home or school and returned it a week later in a sealed envelope to their school secretaries. This procedure was adopted to ensure that the teachers could complete the questionnaire at their convenience without the monitoring of school administrators. To ensure that the questionnaire was anonymous, the teachers were informed that their data would be reported collectively and used for research purposes only. In the returned questionnaires, 182 had complete data and were used for analyses in the present study. The attrition rate was $14 \%$.

\section{Results}

Descriptive statistics and bivariate correlations for all the measures are presented in Table 2. Our theoretical model (see subchapter 1.3.1. Hypotheses) predicting teacher attitude for future persistence in project-based learning was estimated with LISREL 8.8 (Jöreskog \& Sörbom, 2007). It was expected that teacher motivation would partially mediate the effect of school support on teacher attitude for future persistence in project-based learning. Both direct and indirect effects of school support on teacher attitude for future persistence were expected. The theoretical model contained one exogenous variable, namely Perceived School Support, and two endogenous variables, namely Teacher Motivation and Attitude for Future Persistence. The latent construct of Perceived School Support was measured with three indices, namely Competence Support, Autonomy Support, and Collegial Support. The latent 
construct of Teacher Motivation was measured with five indices, whereas the latent construct of Attitudes for Future Persistence was measured with two indices. The LISREL results showed that the proposed model fit reasonably well with the data, $\chi^{2}(32, \underline{\mathrm{N}}=182)=77.53, \underline{\mathrm{p}}<.001 ; \mathrm{CFI}=.98, \mathrm{SRMR}=.04$, and $\mathrm{AIC}=123.53$.

Insert Table 2 about here

The structural and measurement coefficients of the model are presented in Figure 1. The path between Perceived School Support and Teacher Motivation was significant statistically, $\beta=.71, \mathrm{p}<.001$, suggesting that teachers would report high motivation in the project-based learning program when they perceived their schools as being strong in collegiality and supportive of their competence and autonomy. The path between Teacher Motivation and Attitude for Future Persistence was also significant statistically, $\beta=.60, \mathrm{p}<.001$, suggesting that the more the teachers reported that they were motivated, the more they were willing to continue with project-based learning in their schools. The direct path between perceived school support and teacher persistence was also significant statistically, $\beta=.39, \mathrm{p}<.001$.

\section{Insert Figure 1 about here}

The Sobel test (Preacher \& Hayes, 2004) was conducted to examine the mediation effect. The results indicated that the mediation effect was significant statistically, $\underline{z}=5.75, \underline{p}<.001$. Taken as a whole, the results suggested that perceived school support had both direct and indirect effects on teacher willingness to continue with project-based learning. Both hypotheses of the present study were supported.

\section{Discussion}

This study, conducted during a time of worldwide education reforms, helps to identify the important components of school support and how this perceived support in turn is related to teacher motivation to implement project-based learning. The results showed that when teachers perceived their school as being stronger in collegiality, and more supportive of their competence and autonomy, they had a higher degree of self-determination in implementing project-based learning and stronger attitude of persistence in this educational innovation. School support had both direct and indirect effects on teacher attitude for persistence in project-based learning. It predicted teacher attitude for future persistence directly and indirectly through its influence on teacher motivation. The direct path between school support and teacher persistence may suggest that apart from the three aspects of school support, the actual infrastructure provided by the school, such as class size, workload allocation and financial resources, have direct impact on teacher attitude.

\subsection{Perceived school support and teacher motivation}

Self-determination theory was developed in the West. With a few exceptions (Vansteenkiste, Zhou, Lens, \& Soenens, 2005), most of the relevant studies were conducted in the West. The present study of Chinese teachers has shown the important role of competence, autonomy, and relatedness across cultures. The importance of these three basic psychological needs is not restricted to the West. The motivation of Chinese teachers in project-based learning is subject to the fulfillment of these three 
basic psychological needs.

The findings of the present study provide timely information to educators who advocate project-based learning. Knowledge about how perceived school support can motivate teachers is instrumental for educators who wish to maximize the application of this new teaching approach and minimize its chances of being rejected or marginalized. The findings also suggest that teacher motivation is predicted by three important dimensions of school support, namely competence support, autonomy support, and collegial support. Previous studies on teacher motivation focused mostly on one or two of these dimensions. For example, Pellettier et al. (2002) investigated how environmental constraints diminished teachers' autonomy and self-determination in teaching. However, they did not include the needs for competence and relatedness in their investigation. Similarly, Ishler et al. (1998) investigated how collegial support affected teachers' long-term implementation of cooperative learning, but the needs for competence and autonomy were not included in their investigation. The present study complemented and extended these previous studies by including all three basic psychological needs for competence, autonomy, and collegial support. It provides a more comprehensive account of the social-contextual factors that are pertinent to the enhancement of teacher motivation. This comprehensive account is consistent with the propositions of self-determination theory (Ryan \& Deci, 2000).

Teacher motivation is pivotal in the implementation of educational innovations, such as cooperative learning (Abrami et al., 2004; Ishler et al., 1998), multi-media instruction (Hobbs, 2004), use of technology (Orrill, Hannafin, \& Glazer, 2004), and bullying prevention programs (Kallestad \& Olweus, 2003). Although the present research focused on teacher motivation in project-based learning, the implications of our findings may be applicable to the implementation of other innovative measures in education reform. The application will be particularly relevant when the innovative measures are very much different from the existing practices. In Hong Kong, teacher-centered approaches, such as direct instruction, are the prevailing teaching approaches. It takes much motivation from the teachers to make drastic changes to the teaching approaches to which they have been accustomed for years. The current study has shown that schools that support competence, autonomy, and collegiality tend to have teachers who are motivated to make such changes.

\subsection{Limitations of the study}

Despite its contributions to the body of knowledge about school support and teacher motivation in the implementation of project-based learning as an education innovation, the present study has some limitations. One limitation is its dependence on self-report measures from teachers. There is a possibility of inflation of correlations when variables are measured at the same time from the same participants (Woolfolk Hoy, 2008). Although self-reports are valid measures of subjective psychological constructs such as motivation in participation and attitude for future persistence, the results of the present study would be much stronger if measures other than self-reports were included. For example, the attitude for future persistence in project-based learning can be measured with behavioral measures such as teachers' choice to participate in the program during the next school year. This behavioral measure might provide stronger evidence for teacher willingness to continue with project-based learning. However, given the fact that participation in the new measures of education reform had a strong mandatory flavor the validity of choice as a behavioral measure could be compromised. 
The measurement of the three dimensions of school support would also be strengthened if objective measures were included. Objective measures might include the tangible support observed in school such as staff development activities on project-based learning, time allowed for project completion, and resources available to teachers. These objective measures would provide relevant information about school support and would complement teacher self-reports. Such measures also support multi-level modeling which is the best approach to address organizational influences on individuals. As suggested by Alexander (2008), different measures have their own strengths and limitations, and researchers are recommended to use different methodologies in conjunction to collect converging evidence.

The present study is a correlational study using naturalistic data. Because of this limitation, causal relations between variables cannot be ascertained. For example, the analysis of structural equation modeling supported a model in which teacher motivation was partially mediating the effect of school support on teacher attitude for future persistence. This means that teacher perception of school support predicted teacher motivation and persistence. Nevertheless, it is equally plausible to say that teacher motivation and persistence predicted teacher perception of school support. In fact, we had tested this alternative model with structural equation modeling and obtained a reasonable goodness of fit, $\chi^{2}(32, \underline{N}=182)=77.53, \underline{\mathrm{p}}<.001$; CFI $=.98$, SRMR $=.04$, and AIC $=123.53$. The results of this alternative model imply that the causal relationships among these school support, teacher motivation, and persistence are equivocal. As Grouzet, Vallerand, Thill, and Provencher (2004) point out, highly self-determined people may perceive environmental factors as being more autonomy supportive than less self-determined people. Since the teacher self-report data of the present study were correlational, it is possible that teachers who were more motivated perceived their schools as being stronger in collegiality, more supportive to their competence and autonomy than teachers who were less motivated. To ascertain causal relations between social-contextual variables and personal variables, some researchers (Grouzet et al., 2004) suggest that one should manipulate social-contextual variables in laboratory experiments. However, school support is not something that researchers can manipulate in a laboratory. As a result, they need to rely on field studies for their investigation of support and its impact on teacher motivation. Nevertheless, it is possible to adopt quasi-experimental design in field studies. For example, they can measure some aspects of school support (e.g., the modes of training the teachers receive in school) and then investigate how the different modes of training can affect teacher motivation. Another possibility is to employ longitudinal designs that allow time series analyses in field studies. With longitudinal data, one can justify the ordering of variables and possible causal effects according to the time of measurement. For example, if we measure teacher motivation at Time 1, school support at Time 2 and then teacher motivation again at Time 3, we can examine the prediction of an effect of school support on the change of teacher motivation. Yet, longitudinal data is still correlational and cannot establish causality.

The present findings are timely in this period of education reform for innovative teaching practices. In spite of its limitations, the present study provides a comprehensive account of the social-contextual factors that are pertinent to the enhancement of teacher motivation in a non-Western cultural setting. Consistent with the propositions of self-determination theory, the findings show that when school is stronger in collegiality and more supportive of teachers' competence and autonomy, teachers are more motivated in using project-based learning and are more willing to continue using this educational innovation in the future. 


\section{Appendix A. Subscales of the Perceived School Support inventory}

Competence support

1. My school provided clear guidelines to us so that I know how to guide my students.

2. My school provided sufficient training to us so that I know how to implement project-based learning.

3. The timetable for implementing project-based learning was reasonable in my school so that I could do well on the task.

4. My school took my workload into account, gave me room and time to do well on project-based learning.

5. There was good coordination in my school so that I could complete my task smoothly.

\section{Autonomy support}

1. I was involved in formulating the direction and contents of project-based learning.

2. My school sought teachers' opinions widely in the process.

3. I participated voluntarily in the project-based learning.

4. I had a certain degree of freedom to decide how to supervise my students.

5. I felt that my opinions were respected in the process.

Collegial support

1. I got encouragement from my colleagues when I encountered difficulties in project-based learning.

2. Many colleagues shared useful resources with me.

3. Many colleagues shared their experience with me regarding the skills in supervising project-based learning.

4. Many colleagues cared about the difficulties I faced in the process.

5. My colleagues and I made a concerted effort to implement project-based learning.

\section{Appendix B. Subscales of the Teacher Motivation inventory}

\section{External regulation}

1. I participated because it was the duty assigned by my school.

2. I participated because it was the requirement from my school.

3. I participated because it was the current policy in my school.

4. I participated because my supervisor would assess my work performance.

5. I participated because my supervisor would be upset if I didn't.

Introjected regulation

1. I participated because I would feel embarrassed to explain to others my absence.

2. I participated because I could demonstrate to others my willingness to accept new things. 
3. I participated because I would feel uncomfortable if I refused to get involved.

4. I participated because I would like to strive for good performance.

5. I participated because I don't want others to think that I am incapable of doing it.

Identified regulation

1. I participated because it involves important things that I should learn.

2. I participated because it is an important teaching strategy.

3. I participated because it is helpful to my students.

4. I participated because mastering the instructional skills involved can enhance my teaching quality.

5. I participated because it is worthwhile to be promoted.

Intrinsic motivation

1. I participated because I am interested in it.

2. I participated because I feel happy for helping students to overcome the problems they face in the process.

3. I participated because I am interested in knowing more about its instructional skills. 4. I participated because learning new teaching approaches is enjoyable.

5. I participated because I feel satisfied when I can overcome the obstacles in the process.

\section{Acknowledgments}

The authors wish to thank Emily Bao, Eva Chan, Felix Chan, Joanne Chan, William Ma, Connie Ng, Peter Shea, and Lydia Tso for their assistance in data collection. Appreciation is expressed to the teachers and students who participated in the study.

\section{References}

Abrami, P. C., Poulsen, C., \& Chambers, B. (2004). Teacher motivation to implement an educational innovation: Factors differentiating users and non-users of cooperative learning. Educational Psychology, 24, 201-216.

Alexander, P. A. (2008). Charting the course for the teaching profession: The energizing and sustaining role of motivational forces. Learning and Instruction, 18, 483-491.

Bao, X. H., \& Lam, S.-f. (2008). Who makes the choice? Rethinking the role of autonomy and relatedness in Chinese children's motivation. Child Development, 79, 269-283.

Blumenfeld, P. C., Soloway, E., Marx, R. W., Krajcik, J. S., Guzdial, M., \& Palincsar, A. (1991). Motivating project-based learning: Sustaining the doing, supporting the learning. Educational Psychologist, 26, 369-398.

Boggiano, A. K., \& Ruble, D. N. (1979). Competence and the overjustification effect: A developmental study. Journal of Personality and Social Psychology, 74, 1681-1695. 
Briscoe, C. (1991). The dynamic interactions among beliefs, role metaphor, and teaching practices: A case study of teacher change. Science Education, 75 , 185-199.

Carrera, L. I. N., Tellez, T. S. E., \& D’Ottavio, A. E. (2003). Implementing a problem-based learning curriculum in an Argentinean medical school: Implications for developing countries. Academic Medicine, 78, 798-801.

Cohen, J., \& Cohen, P. (1983). Applied multiple regression/correlation analysis for the behavioral sciences (2nd ed.). Hillsdale, NJ: Erlbaum.

Curriculum Development Council. (2001). The way forward in curriculum development: Learning to learn. Hong Kong: Government Printer.

Deci, E. L. (1971). The effects of externally mediated rewards on intrinsic motivation. Journal of Personality and Social Psychology, 18, 105-115.

Deci, E. L., \& Cascio, W. F. (1972, April). Changes in intrinsic motivation as a function of negative feedback and threats. Paper presented at the Eastern Psychological Association, Boston, MA.

Deci, E. L., \& Ryan, R. M. (1985). Intrinsic motivation and self-determination in human behavior. New York: Plenum.

Deci, E. L., \& Ryan, R. M. (1991). A motivational approach to self: Integration in personality. In R. Dienstbier (Ed.), Nebraska symposium on motivation: Perspectives on motivation (Vol. 38) (pp. 237-288). Lincoln, NE: University of Nebraska Press.

Deci, E. L., \& Ryan, R. M. (2000). The "what" and "why" of goal pursuits: Human needs and the self-determination of behavior. Psychology Inquiry, 11, 227-268.

Dewey, J. (1938). Experience and education. New York: Macmillan.

Education Commission. (2000). Learning for life, learning through life: Reform proposal for the education system in Hong Kong. Hong Kong: Government Printer.

Evertson, C. M., \& Weinstein, C. S. (Eds.). (2006). Handbook of classroom management: Research, practice, and contemporary issues. Mahwah, NJ: Erlbaum.

Fullan M., \& Hargreaves, A. (1997). What's worth fighting for in your school (2nd ed.). New York: Teacher College Press.

Fullan, M. (2000). The return of large-scale reform. Journal of Educational Change, 1, 5-28.

Grolnick, W. S., \& Ryan, R. M. (1987). Autonomy in children's learning: An experimental and individual difference investigation. Journal of Personality and Social Psychology, 52, 890-898.

Grolnick, W. S., Ryan, R. M., \& Deci, E. L. (1991). The inner resources for school achievement: Motivational mediators of children's perceptions of their parents. Journal of Educational Psychology, 83, 508-517.

Grouzet, F. M. E., Vallerand, R. J., Thill, E. E., \& Provencher, P. J. (2004). From environmental factors to outcomes: A test of an integrated motivational sequence. Motivation and Emotion, 28, 331-346.

Guttman, L. ( 1954). A new approach to factor analysis: The Radex. In P. Lazarfeld (Ed.), Mathematical thinking in the social sciences (pp. 258-348). New York: Free Press of Glencoe.

Hobbs, R. (2004). A review of school-based initiatives in media literacy education. American Behavioral Scientist, 48, 42-59.

Hu, L., \& Bentler, P. M. (1995). Evaluating model fit. In R. H. Hoyle (Ed.), Structural equation modeling: Concepts, issues, and applications (pp. 76-99). 
Thousand Oaks, CA: Sage.

Hu, L., \& Bentler, P. M. (1999). Cutoff criteria for fit indexes in covariance structure analysis: Conventional criteria versus new alternatives. Structural Equation Modeling, 6, 1-55.

Ishler, A. L., Johnson, R. T., \& Johnson, D. W. (1998). Long-term effectiveness of a statewide staff development program in cooperative learning. Teaching and Teaching Education, 14, 273-281.

Iyengar, S. S., \& Lepper, M. R. (1999). Rethinking the value of choice: A cultural perspective on intrinsic motivation. Journal of Personality and Social Psychology, 76, 349-366.

Jesus, S. N., \& Lens, W. (2005). An integrated model for the study of teacher motivation. Applied Psychology: An International Review, 54, 119-134.

Jöreskog, K. G., \& Sörbom, D. (2007). LISREL 8.8: User’s reference guide. Chicago: Scientific Software.

Kallestad, J. H., \& Olweus, D. (2003). Predicting teachers' and schools' implementation of the Olweus Bullying Prevention Program: A multilevel study. Prevention and Treatment, 6, np.

Kim, J. W. (2004). Education reform policies and classroom teaching in South Korea. International Studies in Sociology of Education, 14, 125-145.

Lam, S.-f., \& Lau, W.-s. (2008). Teachers' acceptance of peer coaching: Impact of collegiality and goal orientation. Journal of School Connections, 1, 3-24.

Lam, S.-f., Yim, P.-s., \& Lam, T. (2002). Transforming school culture: Can true collaboration be initiated? Educational Research, 44, 181-195.

Lewin, K. (1936). A dynamic theory of personality. New York: McGraw Hill.

Malmberg, L.-E. (2008). Student teachers' achievement goal orientations during teacher studies: Antecedents, correlates and outcomes. Learning and Instruction, 18, 438-452.

Markus, H. R., \& Kitayama, S. (1991). Culture and the self: Implications for cognition, emotion, and motivation. Psychological Review, 98, 224-253.

Ohlhausen, M., Meyerson, M., \& Sexton, T. (1992). Viewing innovations through the efficacy-based change model: A whole language application. Journal of Reading, 35, 536-541.

Orrill, C. H., Hannafin, M. J., \& Glazer, E. M. (2004). Disciplined inquiry and the study of emerging technology. In D. H. Jonassen (Ed.), Handbook of research on educational communications and technology (Vol. 2, pp. 335-353). Mahwah, NJ: Erlbaum.

Pelletier, L. G., Seguin-Levesque, C., \& Legault, L. (2002). Pressure from above and pressure from below as determinants of teachers' motivation and teaching behaviors. Journal of Educational Psychology, 94, 186-196.

Preacher, K. J., \& Hayes, A. F. (2004). SPSS and SAS procedures for estimating indirect effects in simple mediation models. Behavior Research Methods, Instruments, and Computers, 36, 717-731.

Rich, Y. (1990). Ideological impediments to instructional innovation: The case of cooperative learning. Teaching and Teacher Education, 6, 81-91.

Ross, J. (1994). The impact of an in-service program to promote cooperative learning on the stability of teacher efficacy. Teaching and Teacher Education, 10, 381-394.

Roth, G., Assor, A., Kanat-Maymon, Y., \& Kaplan, H. (2007). Autonomous motivation for teaching: How self-determined teaching may lead to self-determined learning. Journal of Educational Psychology, 99, 761-774. 
Ryan, R. M., \& Connell, J. P. (1989). Perceived locus of causality and internalization: Examining reasons for acting in two domains. Journal of Personality and Social Psychology, 57, 749-761.

Ryan, R. M., \& Deci, E. L. (2000). Self-determination theory and the facilitation of intrinsic motivation, social development, and well-being. American Psychologist, 55, 68-78.

Ryan, R. M., Stiller, J., \& Lynch, J. H. (1994). Representations of relationships to teachers, parents, and friends as predictors of academic motivation and self-esteem. Journal of Early Adolescence, 14, 226-249.

Saye, J. W., \& Brush, T. (2004). Scaffolding problem-based teaching in a traditional social studies classroom. Theory and Research in Social Education, 32, 349-378.

Sleeter, C. (1992). Restructuring schools for multicultural education. Journal of Teacher Education, 43, 141-148.

Schaarschmidt, U. (Ed.). (2005). Halbtagsjobber? Psychische Gesundheit im Lehrerberuf [Part-time-jobber? Mental health in the teaching occupation]. Weinheim, Germany: Beltz.

Tse, S. K., Lam, W. I., Lam, Y. H., \& Loh, E. K. Y. (2005). Learn to read: The performance of Hong Kong primary 4 pupils in PIRLS 2001. Hong Kong: Hong Kong University Press.

Vansteenkiste, M., Zhou, M., Lens, W., \& Soenens, B. (2005). Experiences of autonomy and control among Chinese learners: Vitalizing or immobilizing? Journal of Educational Psychology, 97, 468-483.

Watkins, D., \& Biggs, J. B. (2001). The paradox of the Chinese learner and beyond. In D. Watkins \& J. B. Biggs (Eds.), Teaching the Chinese learner: Psychological and pedagogical perspective (pp. 3-23). Hong Kong: Comparative Education Research Centre.

Woolfolk Hoy, A. (2008). What motivates teachers? Important work on a complex question. Learning and Instruction, 18, 492-498.

Zeichner, K. M. (1991). Contradictions and tensions in the professionalization of teaching and the democratization of schools. Teachers College Record, 92, 363-379. 
Table 1

Correlations between the subscales of the Teacher Motivation inventory and the two items measuring attitude for future persistence

\begin{tabular}{lll}
\hline & \multicolumn{2}{c}{ Attitude for future persistence } \\
\cline { 2 - 3 } Teacher motivation & Negative attitude & Positive attitude \\
\hline External & $.38^{* * a}$ & $-.22^{* * a}$ \\
Introjected & $.06^{\mathrm{ab}}$ & $.05^{\mathrm{ab}}$ \\
Identified & $-.74^{* * \mathrm{~b}}$ & $.75^{* * \mathrm{~b}}$ \\
Intrinsic & $-.78^{* *}$ & $.76^{* *}$ \\
\hline
\end{tabular}

${ }^{* *} \mathrm{p}<.01$. The adjacent correlation coefficients in the same column that share the same superscript are significantly different from each other at .05 level.

Table 2

Descriptive statistics and bivariate correlations between the variables of the study

\begin{tabular}{|c|c|c|c|c|c|c|c|c|c|c|c|}
\hline Variable & $\begin{array}{l}\text { Mean } \\
\text { (SD) }\end{array}$ & 1 & 2 & 3 & 4 & 5 & 6 & 7 & 8 & 9 & 10 \\
\hline Competence support & $\begin{array}{l}3.43 \\
(1.05)\end{array}$ & -- & & & & & & & & & \\
\hline Autonomy support & $\begin{array}{l}3.66 \\
(.94)\end{array}$ & $.81^{* *}$ & -- & & & & & & & & \\
\hline Collegial support & $\begin{array}{l}3.41 \\
(.98)\end{array}$ & $.68 * *$ & $.73 * *$ & -- & & & & & & & \\
\hline Teacher motivation 1 & $\begin{array}{l}2.04 \\
(4.52)\end{array}$ & $.62 * *$ & $.60 * *$ & $.53 * *$ & -- & & & & & & \\
\hline Teacher motivation 2 & $\begin{array}{l}1.13 \\
(4.21)\end{array}$ & $.42 * *$ & $.47 * *$ & $.40 * *$ & $.66^{* *}$ & -- & & & & & \\
\hline Teacher motivation 3 & $\begin{array}{l}1.05 \\
(3.97)\end{array}$ & $.48^{* *}$ & $.50 * *$ & $.44 * *$ & $.67 * *$ & $.61^{* *}$ & -- & & & & \\
\hline Teacher motivation 4 & $\begin{array}{l}.54 \\
(4.27)\end{array}$ & $.53^{* *}$ & $.54 * *$ & $.44^{* *}$ & $.67 * *$ & $.69 * *$ & $.67 * *$ & -- & & & \\
\hline Teacher motivation 5 & $\begin{array}{l}1.80 \\
(5.43)\end{array}$ & $.46^{* *}$ & $.51^{* *}$ & $.44 * *$ & $.67 * *$ & $.73 * *$ & $.73 * *$ & $.74 * *$ & -- & & \\
\hline Teacher persistence 1 & $\begin{array}{l}3.31 \\
(1.43)\end{array}$ & $.62 * *$ & $.64 * *$ & $.49 * *$ & $.73 * *$ & $.64 * *$ & $.58 * *$ & $.69 * *$ & $.62 * *$ & -- & \\
\hline Teacher persistence 2 & $\begin{array}{l}3.90 \\
(1.26)\end{array}$ & $.65^{* *}$ & $.62 * *$ & $.43^{* *}$ & $.64 * *$ & $.50 * *$ & $.55^{* *}$ & $.61^{* *}$ & $.52 * *$ & $.72 * *$ & -- \\
\hline
\end{tabular}

The scores of Teacher motivation 1 through 5 are the five indices of teachers' level of self-determination. Scores range from -15 to 15 , with 0 as the mean. High score indicates high self-determination and low score indicates low self-determination.

Numbers in parentheses are standard deviations.

$* * \mathrm{p}<.01$. 


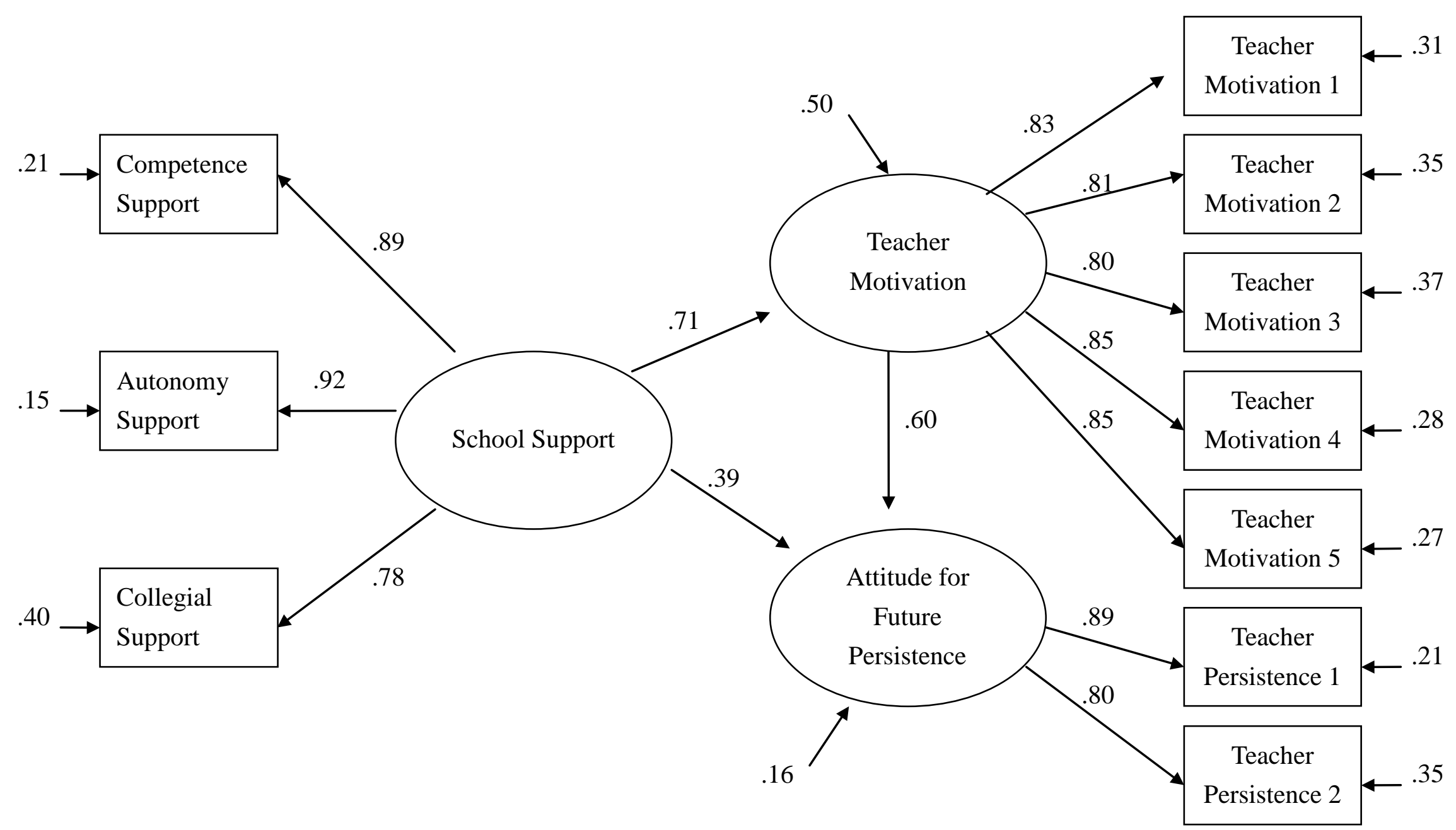

Fig. 1. Path diagram of the model with standardized maximum likelihood estimates. 